\title{
On Determining Factors for Good Research in Biomedical and Health Informatics
}

\section{Some Lessons Learned*}

\section{R. Haux}

Peter L. Reichertz Institute for Medical Informatics, University of Braunschweig - Institute of

Technology and Hannover Medical School, Germany

\section{Background and Objective}

Objective: What are the determining factors for good research in medical informatics or, from a broader perspective, in biomedical and health informatics?

Method: From the many lessons learned during my professiona career, I tried to identify a fair sampling of such factors. On the occasion of giving the IMIA Award of Excellence lecture during Medlnfo 2013, they were presented for discussion.

Results: Sixteen determining factors (df) have been identified: early identification and promotion (dfl), appropriate education (df2), stimulating persons and environments (df3), sufficient time and backtracking opportunities (df4), breadth of medical informatics competencies (df5), considering the necessary preconditions for good medical informatics research (df6), easy access to high-quality knowledge (df7), sufficient scientific career opportunities (df8), appropriate conditions for sustainable research (dF9), ability to communicate and to solve problems (df10), as well as to convey research results (df 1 1) in a highly inter- and multidisciplinary environment, ability to think for all and, when needed, taking the lead (df12), always staying unbiased (df13), always keeping doubt (df14), but also always trying to provide solutions (df15), and, finally, being aware that life is more (dfl6).

Conclusions: Medical Informatics is an inter- and multidisciplinary discipline "avant la lettre". Compared to monodisciplinary research, inter- and multidisciplinary research does not only provide significant opportunities for solving major problems in science and in society. It also faces considerable additional challenges for medical informatics as a scientific field. The determining factors, presented here, are in my opinion crucial for conducting successful research and for developing a research career. Since medical informatics as a field has today become an important driving force for research progress, especially in biomedicine and health care, but also in fields like computer science, it may be helpful to consider such factors in relation with research and education in our discipline.

\section{Keywords}

Medical informatics, biomedical informatics, health informatics, research, interdisciplinary research, multidisciplinary research.

Yearb Med Inform 2014:255-64

http://dx.doi.org/10.15265/IY-2014-0025

Published online May 22, 2014

\subsection{Objective}

What constitutes good research in medical informatics or, from a broader perspective, in biomedical and health informatics? And, in this context, what are the determining or essential factors for being able to carry out such research? Based on many lessons learned during my professional career, I want to try to identify a fair sampling of such factors and present them for discussion.

\subsection{Two Occasions Motivating this Essay}

Two events have influenced me to write this paper.

The first one took place on May 22nd, 2013, when a symposium was held in Braunschweig, Germany, on 'medical informatics - perspectives of a scientific discipline", coinciding with my $60^{\text {th }}$ birthday. One of the organizers, Alfred Winter, asked me, when preparing the event, who my most important teachers were - and expected a short and immediate response. To my own surprise I could not answer this question and, a couple

\footnotetext{
* This is an extended version of my 'IMIA Award of Excellence' lecture, given on August 23, 2013, at MedInfo 2013 in Copenhagen, Denmark. It is dedicated to Professor Jan Hendrik van Bemmel, University of Rotterdam, one of the most influential leaders in our field for me - and certainly for many other colleagues. I have benefited in my own development significantly from his work and from countless discussions with him during the past three decades.
}

of months later, shortly before the symposium actually took place, I sent him my reply, which finally grew to about 20 pages in length. There I wrote about those persons who had significantly influenced my professional development as a scientist, and included some notes on my personal background [1]. After having written the reply, I discovered that at least as important for my development were certain environments and other factors, which might be considered as factors for determining good research. Whereas the persons, mentioned in [1], were those most important to me and, possibly, to a number of other persons, I thought that sharing lessons learned about determining factors for good research in biomedical and health informatics might be of interest to a broader audience, including, in particular, though not only, young colleagues, who are at the beginning of their scientific careers.

The second event also took place on May 22nd, 2013, when I was informed, to my surprise, that I had been selected to receive the IMIA Award of Excellence for 2013. As a tradition, the recipient of this award usually gives a keynote speech during our medical informatics world congress, which in this case was to be the MedInfo 2013 held in Copenhagen, Denmark. The topic was of my choosing. And it is also tradition that a written version of this talk had to be prepared [2], [3]. Because of its relevance, and because I might be able to contribute, I selected as topic of my talk the above mentioned theme.

\subsection{Structure}

Before presenting the determining factors for good research in medical informatics in section 3, I need to introduce medical 
informatics as a field and highlight and comment on some of its specific aspects in section 2. Some consequences or outcomes of the identified determining factors are then discussed in section 4, followed by a summarizing table and some final remarks in section 5 .

\subsection{Remarks}

As is usual, I will use the term medical informatics in a wide, comprehensive sense. The name medical informatics matches the name of our international association (International Medical Informatics Association, [10]) and is traditionally used in my own environment, as can demonstrate the name of the German Association for Medical Informatics, Biometry and Epidemiology [11] and of the Peter L. Reichertz Institute for Medical Informatics [12]. Others may call this discipline or field biomedical informatics, or health informatics, or biomedical and health informatics, or yet something else. There have been different names used in the past (e.g. [4], [5]) and there may be others in the future.

The determining factors for research presented here are subjectively biased. As mentioned, this paper is intended to put these factors up for discussion. So, maybe, a broader debate will ensue, and these factors can be extended or modified as a result. And, since I was influenced by many discussions with my colleagues during the past decades - mainly by those, mentioned in [1] - for some, if not all of the factors mentioned, credit belongs to them as well.

Determining factors for good research are obviously related to rules for good scientific practice. I will here neither go into this important aspect nor define what 'good' research means, but at least want to refer to [6], [7] as well as [8] and [9] (the last two in German).

Finally, I should mention that several earlier publications on this topic exist. I will refer to and, partially, quote from some of them, but most importantly from those written by one person: Jan Hendrik van Bemmel, Professor emeritus and Past Rector Magnificus of the Erasmus University of Rotterdam, and Past President of IMIA.

\subsection{On Jan van Bemmel}

This essay is dedicated to Jan van Bemmel. He shaped and further developed our discipline in an exceptional way. He strongly influenced not only me, but, without any doubt, a very large number of colleagues in our field.

An appreciation of Jan van Bemmel's achievements can be found in [13] - [15]. In addition to his research accomplishments in various fields, he contributed at the 'meta-level' to focusing medical informatics as a scientific discipline [16] - [20], by publishing two textbooks [21], [22], by founding and for nearly a decade publishing the international summary of research and professional activities in our field - the IMIA Yearbook series [23], [24] -, and by editing for more than 10 years the journal Methods of Information in Medicine [25]. More recently, he shared with us his view on research perspectives, often related to medical informatics as a discipline [3], [26] - [28].

Jan van Bemmel is, at least sometimes, a shy and modest person. I learned this when he did not want to emphasize his own role when, after writing his outstanding paper on 'medical informatics - art or science" [29], I had been asked to comment on it. As editor of the journal Methods at the time, he modified my text accordingly - without asking me as author, whether I agreed. The contrast between what I submitted and what was published is shown in figure 1. This time, I assume and hope that Jan van Bemmel will not have an opportunity to "edit himself out" of my text once again.

\section{What Characterizes Medical Informatics as a Field?}

\subsection{Medical Informatics - a Conventional Definition}

In accordance with [31] and [32], let me define here and in a conventional manner medical informatics as a discipline, concerned with the systematic organization, representation, and analysis of data, information and knowledge in biomedicine and
Box 1 From a commentary [30] on Jan van Bemmel's seminal paper on 'medical informatics, art or science?' [29], which appeared in 1995 in Methods of Information in Medicine. Left column: what was published after Jan van Bemmel's 'editorial modifications'. Right column: my original manuscript - text, deleted by Jan van Bemmel, is highlighted in italics.

Exerpt of a comment on Jan van Bemmel's paper 'medical informatics, art or science?'

\begin{tabular}{|c|c|}
\hline published text & original manuscript \\
\hline $\begin{array}{l}\text { The paper is to some extent summar- } \\
\text { izing and also extending some of his for- } \\
\text { mer papers on the principles of medical } \\
\text { informatics }[2,3] \text {. Besides a variety of } \\
\text { reflections on the potentials and limita- } \\
\text { tions of science, it presents and excel- } \\
\text { lently discusses } 20 \text { examples of research } \\
\text { in medical informatics and the progress } \\
\text { achieved by such research for medicine } \\
\text { and health care. The paper is an impor- } \\
\text { tant step towards systematization and } \\
\text { towards underscoring the necessity of } \\
\text { medical informatics research for medi- } \\
\text { cine and health care. And, by the way, it } \\
\text { also emphasizes its impact for informat- } \\
\text { ics. }\end{array}$ & $\begin{array}{l}\text { The paper is to some extent summarising and also extending } \\
\text { some of his former papers on principles of medical informatics } \\
\text { ([2], [3]). Besides a variety of reflections on the potentials and } \\
\text { limitations of science it presents and excellently discusses } 20 \\
\text { examples of research in medical informatics and on the prog- } \\
\text { ress achieved by such research for medicine and health care. } \\
\text { Jan van Bemmel is one of the most outstanding scientists in } \\
\text { medical informatics with a broad background in both medical } \\
\text { informatics research and education. Those of us that have the } \\
\text { chance to work with him know, that this [is] an honour and } \\
\text { a challenge and, much more, a pleasure. And, consequently, } \\
\text { the paper he is presenting is of high quality and should be } \\
\text { read by everybody in our scientific community. } \\
\text { It is an important step towards systematisation and towards } \\
\text { pointing out the necessity of medical informatics research for } \\
\text { medicine and health care. And, by the way, it also points on } \\
\text { its impact for informatics. }\end{array}$ \\
\hline
\end{tabular}


health care. For solving its problems and for studying its general principles, appropriate methods and tools are used. Besides developing methods of its own and using those of the computer and information sciences in general, medical informatics also uses methods of other disciplines such as mathematics, biometry, economics, linguistics, and physics. Obviously, computers are essential tools for processing data, information, and knowledge.

Systematic organization, representation, and analysis of data, information, and knowledge in biomedicine and health care do not exist for its own sake. Medical informatics is neither sufficiently defined by its methodology and technology on the one hand, nor by its domain on the other, for these methods and tools to be developed and applied. It is also characterized by its objectives, which for medical informatics are twofold: to contribute to the progress of science and to contribute to high-quality, efficient health care, as well as to the quality of life.

\subsection{Another View on Medical Informatics as Discipline}

Motivated by a description of Stephen Senn ${ }^{1}$ on a related field [33], medical informatics might also be described in a different way:

\footnotetext{
"Statistics is a wonderful discipline. It has it all: mathematics and philosophy, analysis and empiricism, as well as applicability, relevance and the fascination of data. It demands clear thinking, good judgement and flair. Statisticians are engaged in an exhausting but exhilarating struggle with the biggest challenge that philosophy makes to science: how do we translate information into knowledge? Statistics tells us how to evaluate evidence, how to design experiments, how to turn data into decisions, how much credence should be given to whom to what and why, how to reckon chances and when to take them. Statistics deals with the very essence of the universe: chance and contingency are its discourse and statisticians know the vocabulary. If you think that statistics has nothing to say about what you do or how you could do it better, then you are either wrong or in need of a more interesting job." Quoted from http://www.senns.demon.co.uk/DICE. html. Last access July 29, 2013.
}

Medical informatics is a wonderful discipline. It deals with organizing, representing, and analyzing data, information, and knowledge in biomedicine and health care. This is done in one of the most important areas for the life of all people in our world. It is engaged in an exhausting, but exhilarating struggle with one of the biggest challenge that science is facing: How do we translate data into information and how do we turn information into knowledge? Working in this field is demanding, it needs clear thinking, good judgement, and flair.

Medical informatics has many facets, all of them are both, challenging and fantastic. Medical informatics ...

1)... is a modelling discipline. It forces us to view and understand medicine and health care better in a very broad and comprehensive manner. This may comprise pathophysiological processes, diseases, decisions, and health information systems (see [34], [35] for more details).

2) ... is an empirical discipline. In the "micro-macro spectrum of medical informatics" [36], it demands both (i) nature (e.g. cells, human beings, populations) and (ii) institutions, devoted to health care and good and healthy living, to provide answers.

$3)$... is an engineering discipline. In medical informatics we are able to do both: In "preparing for change" [37] we may passively observe and comment, but we also can actively change our world by building tools to support diagnosis, therapy, and/or the many other facets in organizing care and healthy living.

4) ... is an organizational discipline. It helps to change processes and organisations in order to make our world better prepared for providing good and affordable care as well as contented, joyful living in dignity and safety.

5) ... aims to contribute to high-quality, efficient health care and to quality of life on the one hand and to progress in science on the other. What could, as its quintessence, be better and more stimulating as objectives than these, for all of us working either in practice or in research or in education?

\subsection{On Relationships with Other Disciplines and a Unique Feature}

Let me from now focus on just one aspect of medical informatics: the one of being a scientific discipline.

In terms of the relationships of medical informatics with other disciplines, two views seem to me worth mentioning here:

- Jointly with other disciplines in biomedicine and in health sciences, medical informatics is devoted to the above-mentioned objectives. Research in this field needs to be assessed on whether its outcomes contribute to high-quality, efficient health care, and to the quality of life on the one hand, and/or to progress in science on the other.

- Jointly with other disciplines, but mainly with computer science, medical informatics uses certain methods and tools. Since the methods needed in medical informatics are aligned with the discipline's objectives, there is not just a simple one-to-one overlap with computer science (denoted Informatik in German; as in many other languages this close relationship becomes very clear in the name informatics). But, when looking at research and education in our field in the last decades, we can observe that the closest relationship here is to computer science, although there are also methods used from other fields like the ones, mentioned in section 2.1. There has been a quite intensive discussion within medical informatics, on whether medical informatics has also its own methodology and to which extent it pushes methodological developments (e.g. [38] - [40] and the already mentioned references [29], [32], [37] for debates from the past as well as [41] - [45] and [46] - [48] for more recent discussions).

As mentioned earlier, medical informatics deals with organizing, representing, and analyzing data, information, and knowledge in biomedicine and health care - which is, by the way the theme or "Leitmotif" - of the journal Methods of Information in Medicine [49], [41] with respect to methodology and scientific foundations.

Medical informatics is not the only discipline here. Medical biometry as well as 
epidemiology can be classified under this thematic umbrella, too. However, medical informatics has also a unique feature, compared to its two sister disciplines. Jointly with medical biometry and epidemiology, medical informatics has an analytic side, discovering new information and knowledge. But, in addition to this analytic side, medical informatics has also an engineering side, designing, and constructing new tools and actively participating in changing institutions and their processes for these purposes. It might be good to be aware of this unique feature and to sustain it in the future development of this field, as it provides also unique opportunities to contribute to scientific progress.

Let me highlight another aspect here. Being closely related, it is probably obvious to observe, among the disciplines, overlaps in the problems to be solved, and in the methods being used. In my opinion it is important to share and discuss such overlapping methodological developments and to have journals like Methods, where this is possible [41, section 4, page 501], [50], [51]).

\subsection{On Being an Inter- and Multidisciplinary Discipline "avant la lettre"}

Let me begin this section with a quote from Jan van Bemmel: "Interdisciplinary research in science and engineering is a mode of research by teams or individuals that uses information, techniques, tools, perspectives, and/or theories from two or more established disciplines to solve problems whose solutions are beyond the scope of a single scientific discipline or area of scientific practice" ([52], where he was quoting [53]). And Jan van Bemmel adds: "Interdisciplinary research is not a category of research but a consequence of addressing a complex question, with methods drawn from multiple disciplines. Research is people, and personal interactions are critical to interdisciplinary research. Collaboration takes extra time to develop, to build consensus and [to] understand new methodologies, language, and culture" [52]. In addition to interdisciplinary research, where fields actively interact and may change by this interaction, the same change occurs for multidisciplinary research, where 'just' knowledge of more than one scientific field is needed for solving problems (see e.g. [54] for definitions).

Because of its objectives, its domain, its methods and tools, medical informatics is an exceptionally highly inter- and multidisciplinary discipline "avant la lettre" [52]. In other words: problems, where medical informatics competencies are needed in order to be solved, are usually problems, where more than one discipline is involved and where multi- or even interdisciplinary collaboration is necessary. My experience, which is based on my work over the past decades and on many talks with colleagues, working in other fields, suggests that the degree and the intensity of inter- and multidisciplinary nature of research questions in medical informatics is very high. This has tremendous consequences.

As mentioned before, collaboration takes extra time. It might be also very stimulating - this is at least my experience ("exhausting, but exhilarating", see section 2.2). But being able to successfully work in the context of many scientific 'cultures' is an additional challenge for medical informatics as a field and, as consequence, for those doing research in this field. Experience and willingness for interdisciplinary cooperation is a 'must' in medical informatics. And, besides many other medical informatics competencies (see next section 2.5) for such inter- and multidisciplinary work, it is also very critical to have sufficient knowledge and/or skills:

- of the corresponding health systems, in particular of health care processes;

- of functionalities and architectures of health information systems (including, e.g., standards);

- on how to successfully integrate new functionalities, considering both technical and organizational aspects (which itself urgently needs knowledge of health care processes and information system architectures - details of integration types may e.g. be found in [55], section 6.5);

- of user needs (such as health care professionals needs);

- on how to run projects in the context of strategic and tactical information management (definitions for such information management levels may e.g. be found in [55], sections 3.4 and 9.2).

And we should not forget that, although we are working in a multi- and interdisciplinary context, "each team member should be an expert in at least one mono-discipline" [27], which holds also for those working in medical informatics.

Let me quote Jan van Bemmel once more: "As said, taking a multidisciplinary approach towards the solution of major scientific problems is often the right way to go. It should be mentioned at the same time, that fundamental monodisciplinary research is still of utmost importance, such as the research in the Large Hadron Collider in Geneva or the ITER project in Grenoble. Nevertheless, for large problems in society, such as the changing climate, the energy crisis, or the provision of advanced health care, a multidisciplinary approach is the proper direction to take." ([52], ITER means here International Thermonuclear Experimental Reactor).

And let me share another experience. Because of its ability to conduct inter- and multidisciplinary research and to run projects, it seems to me that medical informatics has an important role in leading such interand multidisciplinary research projects [56].

\subsection{On Medical Informatics Education}

The various ways to learn medical informatics, or educate medical informaticians, are based on the field's above-mentioned objectives, its domain, its methods and tools. Here we can also recognize the inter- and multidisciplinary character of the discipline, as there are various ways of how to learn to systematically - and, as a consequence, professionally - organize, represent, and analyse data, information, and knowledge in biomedicine and health care. Fortunately, during the last decades an international consensus has emerged regarding education in medical informatics, which has recently been promulgated as official recommendations on biomedical and health informatics education by IMIA [57], and which is now used and considered in many national and international activities (e.g. [58] - [63]). 


\subsection{On the Future of Medical Informatics}

A final aspect, which I want to mention in this section 2, concerns the future of medical informatics. And here I will quote Jan van Bemmel for the penultimate time: "I expect that in a couple of years medical informatics will follow the same road as other disciplines, such as medical physics, clinical chemistry and even physiology and genetics: full integration with the specialties and branches of basic and clinical medicine and health care." [28]. My opinion differs to some extent: "health care is in continuous change just as the sciences are in continuous transformation. Medical informatics as discipline is affected by these changes. Within the sciences, medical informatics plays a critical role in bridging the health and information sciences ... . ... the boundaries between disciplines may shift and may lead to a coalescing of medical informatics and other disciplines. Such a coalescing might also result in partially integrating or even fully absorbing medical informatics research in other disciplines like biomedicine, health sciences and computer science." Or, of course, it may also be reversed, that medical informatics is, through its inter- and multidisciplinary character, successfully including (parts of) other fields under the umbrella of this discipline. "This is in my point of view mainly depending on whether medical informatics is willing and successful in taking over itself or whether it is not." (quoted from [32], related work can be found in [64] - [73]).

\section{On Determining Factors for Good Research}

Let me now present 16 factors, which in my opinion are determining or essential factors for good research in medical informatics or, if you wish, in biomedical and health informatics. They will be denoted as $\mathrm{df}_{x}, x$ $\in\{1, \ldots, 16\}$.

For identifying these factors, I have used my report in [1]. As already mentioned in section 1 , I will here try to generalize what has been written there, and will therefore leave out personal notes as well as names of persons who have significantly influenced my professional development.

The 16 factors may be determining factors for many, if not most scientific disciplines. But they have been collected from my viewpoint, i.e. from working and doing research in medical informatics as an exceptionally highly inter- and multidisciplinary field. As also mentioned, the determining factors are subjective and are based on the lessons learned during my scientific career. I will not make an attempt to retrospectively deduce or justify these factors. Others may have had other experiences and could, probably, consider other factors.

\section{df $_{1}$ The factor of early identification and promotion}

Individuals, who are interested - or, maybe better stated, curious [3] - about conducting research, should be identified, encouraged, and promoted as early as possible. This may start as early as preschool, but definitely during the school years. It continues later at university. Identification, stimulation, and promotion should be independent of an individual's background, geographical and cultural origins, or family circumstances, in terms of education, income, and the status of her/his parents.

Through early identification and promotion, all persons, but especially those who appear most disposed towards scientific inquiry, should be encouraged in their curiosity, and afforded the opportunities to carry out research and so to contribute hopefully to accelerating progress in science for the sake of our societies. This should go beyond those, who already have a better chance because of the education, enlightenment, and economic condition of their parents, who encourage and have the wherewithal to promote their children in their studies.

\section{$\mathrm{df}_{2}$ The factor of an appropriate education} Here I want to focus on university education, the most critical educational phase for individuals conducting research in medical informatics subsequently. Different ways exist for becoming a medical informatician. They are described in the IMIA recommendations on education [57]. In all educational approaches, a few aspects are of greatest importance. I want to highlight three.
First, an appropriate learning environment is crucial. Such an environment must, in my opinion, promote physical proximity and collaboration with other students as well as having an intense personal contact with inspiring teachers, who themselves must have adequate medical informatics knowledge and experience in research and practice.

Second, the adequate content of the curriculum is critical. This content is different, depending on whether a student is doing her or his studies with a more informatics or a more health care focus ([57], section 4.1). In all cases, a sufficient breadth of medical informatics knowledge and skills must exist in the domain areas (1) biomedical and health informatics core knowledge and skills, (2) medicine, health, and biosciences, health system organisation, and (3) informatics/ computer science, mathematics, biometry (details in [57], section 3), as otherwise she or he will not be able to contribute sufficiently to research (recall section 2.4).

This brings me to the third aspect. Since medical informatics is a highly inter- and multidisciplinary field, it is of greatest importance that during university education, students should already have the chance to be exposed to collaboration and contribution to projects. This exposure is almost always at the beginning a very difficult, but at the end most stimulating, inter- and multidisciplinary situation ${ }^{2}$. The early exposure helps them to better find their own role later and to adequately contribute in solving research problems.

\section{$\mathrm{df}_{3}$ The factor of stimulating persons and environments}

What are the best environments for learning the foundations, and for later conducting successful research in medical informatics? Based on my experience, the best places are research-oriented institutions, which themselves are usually part of universities. The scientific 'spirit' in such institutions is important, especially in how it conveys by example, ways on how to interact with talented and inspiring teachers and colleagues,

\footnotetext{
One example for such a course, on how students can be very early confronted with this challenging inter- and multidisciplinary situation through respective projects, can be found in [74] and [75].
} 
and on how to approach and solve problems. To reiterate, the importance of such a multidisciplinary research environment is paramount, and usually universities offer the best such environments for open and unbiased medical informatics research.

A critical mass of stimulating persons within these institutions is just as important. Here (full) professors and department chairs are certainly essential, as they will serve as role models or as persons to be critically looked at. But of equal importance are all researchers at such institutions, i.e. at the post-graduate, doctoral, and post-doctoral levels. A critical mass of people with a good distribution of competencies will help the incoming medical informatics researcher to better find her or his way. Another essential component of a stimulating research environment for medical informatics is the existence of exciting research projects carried out by multidisciplinary teams.

Finally, one must not underestimate the role of scientific societies as a way of supporting scientific development. These societies exist in many countries at a national level (e.g. GMDS in Germany [11]), and they also exist at the regional (e.g. EFMI for Europe [76]) and, with IMIA ([10]), at the international level. Actively participating, for example in professional society working groups, is an important way for the career of young scientists to blossom, while sharing their ideas and learning from the experiences of others in a range of different medical informatics environments and contexts, not only in academia, but also in industry and education. Here one can also stepwise get into international communication and collaboration. As for science in general, medical informatics research has been, and will continue to be international.

\section{$\mathbf{d f}_{4}$ The factor of sufficient time and backtracking opportunities}

The breadth of knowledge and skills needed in medical informatics research, has already been emphasized. The conventional way of achieving mastery in our discipline, as in all others, is through education $\left(\mathrm{df}_{2}\right)$. Another, less recognized way, is in my opinion, to give medical informatics researchers sufficient time and experiences for their own development as scientists. Metaphorically speaking they must get their time to build their "professional muscles" - in the many parts of their body, not just in the one they might need for their current task.

This includes the ability for medical informatics researchers to identify by themselves the most relevant and original research questions that arise in solving a medical informatics problem. Researchers are much better at finding their own 'golden' way on doing good research, when they have had the experience of having explored other paths, which were not so good, or which might have been even dead ends. In order to be able to do this, it is also of importance to have the time to experience downright wrong approaches where outcomes proved unproductive.

Having this opportunity of exploring right and wrong research tracks, and finding out how and when to backtrack, is in the long term a more effective path to wise practice than the lean and time-efficient approach to research often advocated by those who would turn science into a highly efficient style of specialized problem-solving. To amplify, I am sceptical, especially for doctoral research, about the approach where the research questions as well as the research program have already been fully defined and elaborated by others (usually by the supervisors), rather than by the doctoral student herself/himself. I do not believe that this leads to the students learning how to become good scientists and to be able to conduct creative scientific inquiry. Such a way is, of course, much quicker for obtaining a doctoral degree, but I have profound doubts to whether it is also the best and even the shortest way of obtaining good long-lasting scientific results.

This is why I recommend that young scientists should have the opportunity to find their own way (though within a certain framework and following some guidelines), including detours (which might prove not to be real detours in the end), and that they should have and take time to develop a broad set of skills based on a wide range of knowledge, inquiry, and problem solving approaches. One should not expect 'productivity' (e.g. in terms of research outcomes or of publications) too early and one should not combine this too much and too early with the setting of career targets.

\section{df $_{5}$ The factor of breadth of medical informatics competencies}

This has already been mentioned before a couple of times, so there is no need to repeat it again here, beyond highlighting that this means that medical informatics scientists must have sufficient knowledge and skills in all domain areas mentioned in $\mathrm{df}_{2}$. Again, I would point to the IMIA recommendations on education [57], in which suggestions for a comprehensive body of knowledge and skills have been made.

\section{$\mathrm{df}_{6}$ The factor of considering the nec- essary preconditions for good medical informatics research}

Here I want to focus on a certain facet of good medical informatics research, which is usually carried out in projects. The expected outcomes of such projects should satisfy at least one of the following two qualities:

- They should be relevant to the objectives of medical informatics (as per section 2).

- They should be original, with respect to (new) methodology and/or technology in medical informatics (also see section 2).

If both are satisfied, then the work clearly falls into the category of medical informatics research, and, is both relevant and original, which is, of course, the best outcome and often the most difficult to achieve. If a line of research only satisfies one of these qualities, then one should critically reflect, whether this is truly research in medical informatics. It might also be either research in some other biomedical or health care field or in some other field of computer or information science, but not in medical informatics. If projects do not satisfy any of these qualities, then one has to reflect on whether this is research at all.

\section{$\mathrm{df}_{7}$ The factor of easy access to high-qual- ity knowledge}

Another necessary prerequisite for a good research environment is access to knowledge. This again presents a couple of facets. What is the quality of knowledge, one has access to? High-quality scientific knowledge is usually found in peer-reviewed publications. In medical informatics, these are usually journals and, to some extent, conference proceedings. The opportunity 
as a researcher to access such high-quality knowledge, without investing too much time and money, is an important prerequisite. For medical informatics, there are outstanding knowledge resources like PubMed/Medline [77], institutions like Health on the Net [78], and periodicals like the IMIA Yearbook of Medical Informatics [23], which allow ready public access to and highlight good research.

There are many debates on how best access to research results can be obtained (e.g. [79], [80]). It remains that for easy access, different ways exist (with different opinions on the right way) and that peer-reviewing continues to be the gold standard for high-quality knowledge.

\section{$\mathrm{df}_{8}$ The factor of sufficient scientific career opportunities}

Scientific careers are highly competitive. This is also the case in medical informatics. But, for the best researchers there must be long-term opportunities to pursue their scientific career, i.e. to practise their profession, and to make a living by doing research in medical informatics. Otherwise excellent researchers might stay in the field for only a limited time period and then get lost to the discipline. This means that a sufficient number of, e.g., assistant professor, associate professor, and full professor positions must be available.

\section{df $_{9}$ The factor of appropriate conditions for sustainable research}

In addition to the above-mentioned career opportunities we should keep in mind that substantial research in medical informatics tends to emphasize specific problems and approaches over limited time intervals of about 5 to 10 years. A longer-term vision (in German: a 'long breath') is needed in order to avoid short term "flashes in the pan' (in German: 'straw fires') of research fashion, which can seriously bias outcomes. Research institutions providing long-term research opportunities for medical informatics research become in this way a crucial environment for another determining factor, relevant to both the scientific careers of researchers and the research outcomes of medical informatics as a field. This may to some extent be detrimental to short-term (e.g. 1 to 3 years) research funding, which tends to be more influenced by political or commercial priorities.

\section{df $_{10}$ The factor of the ability to commu-} nicate and to solve problems in a highly inter- and multidisciplinary environment Medical informaticians must be able to successfully participate in and/or lead projects, and, in the context of this presentation, research projects. Difficulties arise because of the very nature of the research, usually done in a highly inter- and multidisciplinary, and as such, complex, and hardly predictable, environment. To contribute to effective solutions for health care problems when project specifications are incomplete or unclear is always a challenge. To tease out and define clearly the underlying scientific questions, and pursue new approaches is an even more difficult challenge. Finally, in addition to having sufficient knowledge and skills in all the mentioned domain areas of medical informatics, some other required knowledge and skills have been mentioned at the end of section 2.4.

$\mathrm{df}_{11}$ The factor of the ability to convey research results in a highly inter- and multidisciplinary environment

There is, on the one hand, written communication, usually in peer-reviewed journals and conference proceedings. But we should not forget the large number of documented reports made to decision makers, or to those for whom the research results may be useful. These include not only patients and health care professionals, but also the administrative and policy-making persons to whom researchers have to respond to or work with (i.e. hospital, insurance, and government entities). And there is on the other hand the oral communication of results. Again, there is a scientific side to this, in particular related to the conferences and their audiences, and those who seek for researchers' information, because they are affected in a variety of ways. Speaking and writing for these different audiences, taking into consideration the more complex multidisciplinary situation, requires experience and training. Research institutions and environments, together with medical informatics societies, are important vehicles for this training.
Let me mention two examples. For many years, a group of editors of the official journals of IMIA have offered courses on writing for publication in biomedical informatics, usually at international medical informatics conferences like MedInfo 2013 (e.g. [80]). And, some journals have established student editorial boards, where doctoral students are getting trained in writing reviews on submitted journal articles.

It should also be highlighted that conferences like MedInfo are another important aspect of this determining factor. They are driven by scientists, not by commercial, political, or other interests. The motto of the MedInfo 2013, 'conducting medical informatics by converging technologies, conveying sciences, and connecting people expresses this factor very well.

\section{$\mathrm{df}_{12}$ The factor of ability to think for all and, when needed, taking the lead}

Let me recall what I mentioned at the end of section 2.5: medical informaticians have to be able to do research in inter- and multidisciplinary frameworks and they also need to know how to successfully manage projects. It seems to me that medical informaticians also quite often take an important role in leading such inter- and multidisciplinary research projects. In transposing this observation into the context of determining factors, this means that medical informatics researchers should be able to have a basic understanding of the other disciplines involved in such research projects, and that they should also be able to take the lead, when needed.

$\mathrm{df}_{13}$ The factor of always staying unbiased For those doing research in medical informatics: remember that you are a scientist! Always stay unbiased, including in your presentations, especially of your research outcomes. I know that this is hard at times for research, mainly triggered by third party funding and where there is the risk that scientists seem to be pushed into the role of marketers. But good scientific practice (recall section 1.4) has always to be paramount in science, and can be especially challenging for medical informatics as a scientific discipline. As a researcher in medical informatics, you have to be a person of trust, informing others in a fair, unbiased manner. 
df $_{14}$ The factor of always keeping doubt Immediately related to the above factor is that of scientific scepticism while doing research in medical informatics: remember that you are a scientist! As a researcher in medical informatics, you should not lose your ability to question or critically pursue doubts about all research outcomes, including your own, to have the will to reproduce them, and to expect that reproducibility is, whenever possible, a necessary given.

\section{df $_{15}$ The factor of also always trying to provide solutions}

For those doing research in medical informatics, it is worth re-emphasizing once again: remember that you are a scientist! So, in addition to what has been mentioned in $\mathrm{df}_{13}$ and $\mathrm{df}_{14}$, do not forget to be also a person who seeks solutions, and intends to lead to these solutions!

\section{df $_{16}$ The factor of being aware that life is more}

In being aware that life is more than just the pursuit of any specific goal or activity, never lose your humour (even when you seriously doubt your own research results). Never lose the ability to enjoy meeting with and learning from people. And, finally, it is my hope that we all have and never lose the ability to stay amazed at this universe and at what can be called the symphony of life.

\section{Consequences?}

What are the consequences, or lessons we can learn from sections 2 and 3 ? In my opinion these should be rather clear for most of us in our own roles within medical informatics.

- In particular (but not only), when one is at the beginning of a career, it might be helpful to consider, whether such determining factors are present in one's 'specific environment".

- Later, if one becomes responsible for running a research institution or leading a research group, it may be helpful to reflect, whether 'your' research institution or group contributes to, or reinforces these determining factors.

- And, if you are responsible for supporting and organizing science (e.g. being in a funding agency, or working in a ministry of science, or being in a leading administrative position at a university), you may reflect, whether in your strategy for maintaining and/or developing research these factors are being supported or not.

Certainly there will be many differences, in what can be regarded as good environments for doing research in medical informatics, depending on the part of the world in which one lives, and on what the appropriate resources are for doing research, whether financial or others.

Last, but not least, on a more personal basis: we should all ask ourselves, what our contributions to good research are in medical informatics. And we may, among others, discover, or recognise that they are not achieved by only orienting research careers focused primarily on financial indicators like the amount of third party funding or on bibliometric indicators of publication success, like impact factors or h-indexes. At least in my opinion, it is not sufficient to assess good research, good research environments, and good strategies for maintaining and/or developing research strategies just by reference to such indicators, although they might be temptingly easy to calculate.

\section{Final Remarks}

Medical Informatics is an inter- and multidisciplinary discipline "avant la lettre". Compared to monodisciplinary research, inter- and multidisciplinary research does not only present significant opportunities for solving major problems in science and in society. It also faces considerable additional challenges. It is my hope that this has become even more evident, by having characterized this discipline and its determining factors for good research in this article. Because medical informatics as a field has become today an important driving force for research progress, mainly in biomedicine and health care, but also in fields like computer science, it may help to be explicitly aware of such factors with respect to research and education in our discipline.

As mentioned before, the presented determining factors, summarized in table 1 , are now up for your discussion.

Let me finally share with you one last quote from Jan van Bemmel. It is from his IMIA Award of Excellence lecture, which I very much liked reading. In his "reflections on curiosity" ([3]) he wrote: "Yes, we are motivated by curiosity, but foremost we are stimulated by our concern for better health

Table 1 Determining factors for good research in bio $_{\text {medical }}$ and health informatics

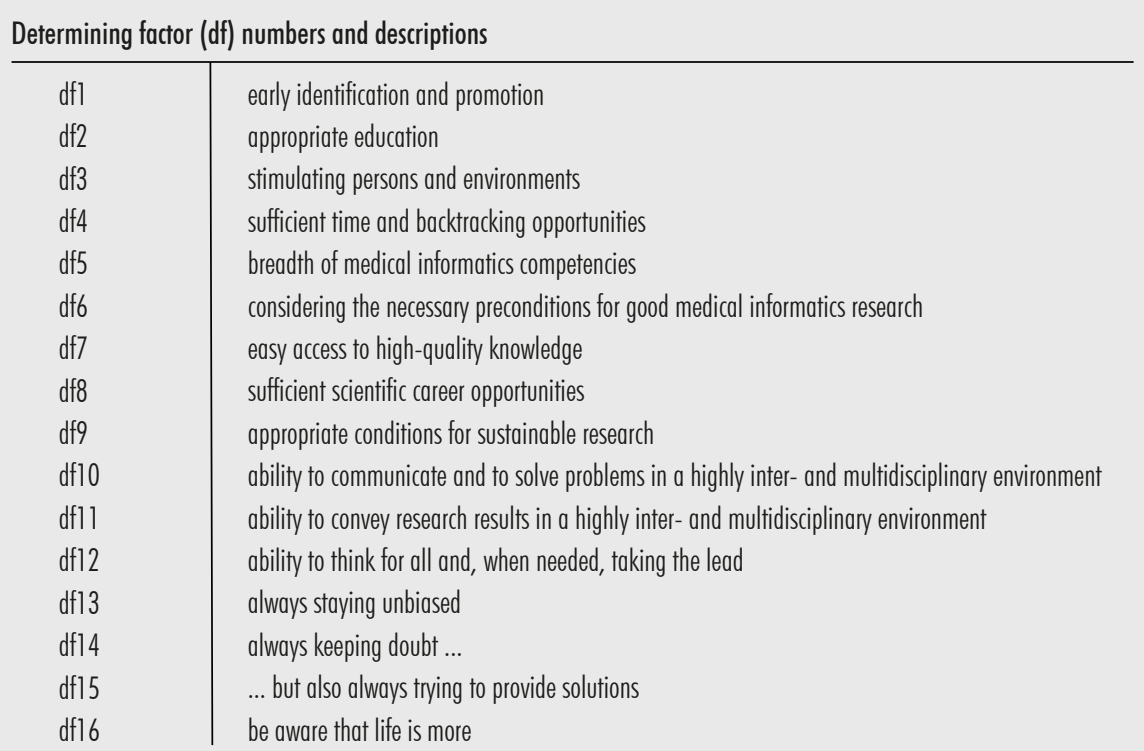


care.” And, going further, Jan van Bemmel asked: "Do we ever question ourselves on what are our deepest motivations and what we are living for?" Doesn't this match with what we all should have, and never lose, i.e. the ability to stay amazed about this universe and what may be called the symphony of life, as mentioned in $\mathrm{df}_{16}$ ?

\section{Acknowledgements}

Alfred Winter's request triggered me to work on reflecting about determining factors. $\mathrm{Ca}$ simir Kulikowski once again kindly agreed to suggest edits of my German-biased English. And also once again he so not only turned this text into a much better readable English style, but he also helped me to reflect on and to sharpen its contents. The IMIA Yearbook editors Marie-Christine Jaulent, Christoph U. Lehmann and Brigitte Séroussi have not only provided the opportunity to publish this text in the IMIA Yearbook 2014, but also supported my suggestion that the paper will be put up for discussion. And, they also helped to significantly improve this manuscript. As mentioned at the beginning, for some, if not for all of the determining factors, I was influenced by many discussions with my colleagues, to whom this article owes much credit - but without making them responsible for my own opinions expressed here! To all of these 'co-authors' I want to express my sincere gratitude.

\section{References}

1. Haux R. „Wer waren Deine wichtigsten Lehrer?“ ["Who where your most important teachers?"]. Manuscript, 2013. GMS Med Inform Biom Epidemiol 2013; 9(3): Doc15. doi: 10.3205/mibe000143, urn:nbn:de:0183-mibe0001434.

2. Grémy F. Hardware, software, peopleware, subjectivity. A philosophical promenade. Methods Inf Med 2005;44: 52-8.

3. van Bemmel JH. Reflections on curiosity. Yearb Med Inform 2008:183-8.

4. Blum B, editor. A framework for medical information science. Med Inform. 1984;9:167-313.

5. Shortliffe EH. The science of biomedical computing. Med Inform 1984;9:185-93.

6. German Research Associacion. Proposals for Safeguarding Good Scientific Practice. Bonn, 1998. http://www.dfg.de/download/pdf/foerderung/ rechtliche_rahmenbedingungen/gute_wissenschaftliche_praxis/self_regulation_98.pdf. Last access: August 22, 2013.

7. Miller RA, Groth T, Hasman A, Safran C, Shortliffe
EH, Haux R, et al. On exemplary scientific conduct regarding submission of manuscripts to biomedical informatics journals. Methods Inf Med 2006;45:1-3.

8. Haux R. Zur Wissenschaftlichkeit in Medizin und Informatik [On good scientific practice in the health and computer sciences]. Informatik-Spektrum 1999;22:276-83.

9. Haux R. Kriterien für gute medizinische Forschung [Criteria for good medical research]. In: Eich W, Bauer AW, Haux R, Herzog W, Rüegg JC, editors. Wissenschaftlichkeit in der Medizin, Teil IV [Good scientific practice, part IV], 181-144. Frankfurt/M.: VAS; 2003.

10. http://www.imia.org. Last access August 12, 2013. 11. http://www.gmds.de. Last access August 12, 2013.

12. http://www.plri.de. Last access August 12, 2013.

13. Haux R, Hasman A, McCray AT, van der Lei J. Is Medical Informatics an Art or a Science? Methods Inf Med 2006;45:651-6.

14. Hasman A, Bergemann D, McCray AT, Talmon JL, Zvárová J. Triangulation applied to Jan $\mathrm{H}$. van Bemmel. Methods Inf Med 2006;45:656-67.

15. Mihalas GI. Romanian medical informatics and professor Jan H. van Bemmel's support - Dr. Honoris Causa bestowed by Victor Babes University. Methods Inf Med 2006;45:668-70.

16. van Bemmel JH. A comprehensive model for medical information processing. Methods Inf Med 1983;22:124-30.

17. van Bemmel JH, Hasman A, Sollet PC, Veth AF. Training in medical informatics. Comput Biomed Res 1983;16:414-32.

18. van Bemmel JH. The structure of medical informatics. Med Inform 1984;9:175-80.

19. van Bemmel JH. The promise of medical informatics. MD Comput 1999;16:15-6.

20. van Bemmel JH. Assessment of education and research in biomedical informatics. Yearb Med Inform 2006:5-10.

21. van Bemmel JH, Willems J, editors. Handboek medische informatica. Utrecht: Bohn, Sheltema \& Holkema; 1989.

22. van Bemmel JH, Musen MA, editors. Handbook of medical informatics. Heidelberg: Springer; 1997.

23. van Bemmel JH, McCray AT, editors. IMIA yearbook of medical informatics, 1992: Advances in an interdisciplinary science; 1993: sharing knowledge and information; 1994: Advanced communications in health care; 1995: The computer-based patient record; 1996: Integration of information for patient care; 1997: Computing and collaborative care; 1998: Health informatics and the Internet; 1999: The promise of medical informatics; 2000: Patient-centered systems. Stuttgart: Schattauer.

24. van Bemmel JH, McCray AT. Advances in an interdisciplinary science. Methods Inf Med 1992;31:235-46.

25. van Bemmel JH. Medical data, information, and knowledge. Methods Inf Med 1988;27:109-10.

26. Musen MA, Van Bemmel JH. Challenges for medical informatics as an academic discipline. Methods Inf Med 2002;41: 1-3.

27. van Bemmel JH. The young person's guide to biomedical informatics. Methods Inf Med 2006;45(6):671-80.

28. van Bemmel JH. People and ideas in medical informatics - a half century review. Yearb Med
Inform 2011;6:175-82.

29. van Bemmel JH. Medical informatics, art or science? Methods Inf Med 1996;35:157-72; discussion 173-201

30. Haux, R. (1996). Medical informatics: once more towards systematisation. Methods Inf Med 1996;35:189-92.

31. Hasman A, Haux R, Albert A. A systematic view on medical informatics. Comput Methods Programs Biomed 1996;51:131-9.

32. Haux R. Medical Informatics: Past, Present, Future. Int J Med Inform 2010;49:599-610.

33. Senn S. Dicing with Death. Cambridge: University Press; 2003.

34. Hasman A, Haux R. Modeling in Biomedical Informatics - An Exploratory Analysis. Part 1. Methods Inf Med 2006;45:638-42.

35. Hasman A, Haux R. Modeling in Biomedical Informatics - An Exploratory Analysis. Part 2. Int J Med Inform 2007;76:96-102.

36. Kulikowski CA. The micro-macro spectrum of medical informatics challenges: from molecular medicine to transforming health care in a globalizing society. Methods Inf Med 2002;41:20-4.

37. Reichertz PL. Preparing for change: concepts and education in medical informatics. Comput Methods Programs Biomed.1987;25:89-101.

38. Blois MS. Medical information science as 'science'. Med Inform 1984;9:181-3.

39. Greenes RA, Shortliffe EH: Medical informatics, an emerging academic discipline and institutional priority. J Am Med Assoc 1990;263:1114-20.

40. Protti DJ, van Bemmel JH, Gunzenhäuser R, Haux $\mathrm{R}$, Warner H, Douglas JV, et al: Can health/medical informatics be regarded as a separate discipline? Methods Inf Med 1995;33:318-26.

41. McCray AT, Gefeller O, Aronsky D, Leong TY, Sarkar IN, Bergemann D, et al. The Birth and Evolution of a Discipline Devoted to Information in Biomedicine and Health Care: As Reflected in its Longest Running Journal. Methods Inf Med 2011;50:491-507.

41. Hasman A, Ammenwerth E, Dickhaus H, Knaup $\mathrm{P}$, Lovis C, Mantas J et al. Biomedical informatics - a confluence of disciplines? Methods Inf Med 2011;50:508-24.

43. Mitchell JA, Gerdin U, Lindberg DAB, Lovis C, Martin-Sanchez FJ, Miller RA et al. 50 Years of Informatics Research on Decision Support: What's Next. Methods Inf Med 2011;50:525-35.

44. Bellazzi R, Diomidous M, Sarkar IN, Takabayashi K, Ziegler A, McCray AT. Data Analysis and Data Mining: Current Issues in Biomedical Informatics. Methods Inf Med 2011;50:536-44.

45. Geissbuhler A, Kimura M, Kulikowski CA, Murray PJ, Ohno-Machado L, Park HA et al. Confluence of Disciplines in Health Informatics: An International Perspective. Methods Inf Med.2011;50: 545-55.

46. Beuscart R. Know thyself. Methods Inf Med 2013; 52:536-7.

47. Elkin PL, Brown SH, Wright G. Biomedical Informatics: We Are What We Publish. Methods Inf Med 2013;52:538-46.

48. Geissbuhler A, Hammond WE, Hasman A, Hussein R, Koppel R, Kulikowski CA, et al. Discussion of 'Biomedical Informatics: We Are What We Publish'. Methods Inf Med 2013;52:547-62.

49. http://www.methods-online.org. Last access 
August 18, 2013.

50. Haux R, Aronsky D, Leong TY, McCray AT. Methods in year 50: preserving the past and preparing for the future. Methods Inf Med 2011;50: 1-6.

51. Bickeböller H, Haux R, Winter A. "Tradition is not preserving the ashes, it is passing on the fire". On strengthening ties with GMDS. Methods Inf Med 2013;52,1-2.

52. van Bemmel JH. Medical informatics is interdisciplinary avant la lettre. Methods Inf Med 2008; 47:318-21.

53. Facilitating Interdisciplinary Research. Washington DC: National Academies Press; 2004.

54. Choi BC, Pak AW. Multidisciplinarity, interdisciplinarity and transdisciplinarity in health research, services, education and policy: 1. Definitions, objectives, and evidence of effectiveness. Clin Invest Med 2006;29:351-64.

55. Winter A, Haux R, Ammenwerth E, Brigl B, Hellrung N, Jahn F. Health Information Systems - Architectures and Strategies. London: Springer; 2011.

56. Haux R, Hein A, Eichelberg M, Appell JE, Appelrath HJ, Bartsch C et al. The Lower Saxony research network design of environments for ageing: towards interdisciplinary research on information and communication technologies in ageing societies. Inform Health Soc Care 2010;35:92-103.

57. Mantas J, Ammenwerth E, Demiris G, Hasman A, Haux R, Hersh W, et al. (IMIA Recommendations on Education Task Force). Recommendations of the International Medical Informatics Association (IMIA) on education in biomedical and health informatics - first revision. Methods Inf Med 2010;49:105-20. Translated and reprinted in various languages.

58. Blas MM, Curioso WH, Garcia PJ, Zimic M, Carcamo CP, Castagnetto JM, et al. Training the biomedical informatics workforce in Latin America: results of a needs assessment. BMJ Open 2011;1:e000233.

59 . Hersh W. The health information technology workforce: estimations of demands and a framework for requirements. Appl Clin Inform 2010;1:197-212.

60. Kampov-Polevoi J, Hemminger BM. A curricula-based comparison of biomedical and health informatics programs in the USA. J Am Med Inform Assoc. 2011;18:195-202.

61. Kulikowski CA, Shortliffe EH, Currie LM, Elkin PL, Hunter LE, Johnson TR, et al. AMIA Board white paper: definition of biomedical informatics and specification of core competencies for graduate education in the discipline. J Am Med Inform Assoc 2012;19:931-8.

62. Röhrig R, Stausberg J, Dugas M; GMDS project group "Medical Informatics Education in Medicine". Development of national competency-based learning objectives "Medical Informatics" for undergraduate medical education. Methods Inf Med 2013;52:184-8.

63. Sarkar IN. Biomedical informatics and translational medicine. J Transl Med 2010;8:22.

64. Geissbuhler A, Kimura M, Kulikowski CA, Murray PJ, Ohno-Machado L, Park HA et al. Confluence of disciplines in health informatics: an international perspective. Methods Inf Med 2011;50:545-55.

65. Hasman A, Ammenwerth E, Dickhaus H, Knaup $\mathrm{P}$, Lovis C, Mantas J, et al. Biomedical informatics - a confluence of disciplines? Methods Inf Med 2011;50:508-24.

66. Kulikowski CA. IMIA: coalescing medical informatics worldwide for 40 years. Yearb Med Inform 2007:176-85. Erratum in: Yearb Med Inform 2008:19.

67. Maojo V, Crespo J, Garcia-Remesal M, de la Iglesia D, Perez-Rey D, Kulikowski CA. Biomedical ontologies: toward scientific debate. Methods Inf Med.2011;50:203-16.

68. Maojo V, Garcia-Remesal M, Bielza C, Crespo J, Perez-Rey D, Kulikowski C. Biomedical informatics publications: a global perspective. Part I: Conferences. Methods Inf Med 2012;51(1):82-90.

69. Maojo V, Garcia-Remesal M, Bielza C, Crespo J, Perez-Rey D, Kulikowski C. Biomedical informatics publications: a global perspective. Part II: Journals. Methods Inf Med 2012;51:131-7.

70. Mitchell JA, Gerdin U, Lindberg DA, Lovis C, Martin-Sanchez FJ, Miller RA, et al 50 years of informatics research on decision support: What's next. Methods Inf Med 2011;50:525-35.

71. Schuemie MJ, Talmon JL, Moorman PW, Kors JA. Mapping the domain of medical informatics.
Methods Inf Med 2009;48:76-83.

72. Shortliffe EH. The future of biomedical informatics: a perspective from academia. Stud Health Technol Inform 2012;180:19-24.

73. Spreckelsen C, Deserno TM, Spitzer K. Visibility of medical informatics regarding bibliometric indices and databases. BMC Med Inform Decis Mak 2011;11:24.

74. Haux R, Ammenwerth E, Häber A, Hübner-Bloder G, Knaup-Gregori P, Lechleitner G, et al. Medical informatics education needs information system practicums in health care settings - experiences and lessons learned from 32 practicums at four universities in two countries. Methods Inf Med 2006:45:294-9.

75. Knaup P, Haux R, Häber A, Lagemann A, Leiner F. Teaching the fundamentals of information systems management in health care. Lecture and practical training for students of medical informatics. Int J Med Inform 1998;50:195-205.

76. http://www.efmi.org. Last access October 6, 2013.

77. http://www.ncbi.nlm.nih.gov/pubmed. Last access October 6, 2013.

78. http://www.hon.ch. Last access October 6, 2013.

79. Wolpert AJ. For the sake of inquiry and knowledge - the inevitability of open access. N Engl J Med 2013;368(9):785-7.

80. Butler D. Investigating journals: The dark side of publishing. Nature 2013;495:433-5.

81. Aronsky D, Talmon J, et al. Writing for publication in biomedical informatics journals. Stud Health Technol Inform 2013;192:1253.

\section{Correspondence to:}

Prof. Dr. Reinhold Haux

Peter L. Reichertz Institute for Medical Informatics

University of Braunschweig - Institute of Technology and Hannover Medical School

Muehlenpfordtstr. 23

D-38106 Braunschweig, Germany

Tel: + 49(0)531 3919500

Fax: +49(0)5313919502

E-mail: Reinhold.Haux@plri.de

www.plri.de 